\title{
A case of an intraocular glass piece that has remained quiescent for four years
}

\author{
Farheen Fatima', Zubaida Sirang', Azam Ali', Nauman Chaudhry', Khabir Ahmad ${ }^{1}$ \\ 'Section of Ophthalmology, Aga Khan University Hospital, Stadium Road, Karachi, Pakistan \\ ${ }^{2}$ Section of Ophthalmology, Mater Misericordiae University Hospital, Dublin, Ireland \\ ${ }^{3}$ Yale School of Medicine, New Haven, United States
}

\begin{abstract}
An intraocular foreign body (IOFB) is mainly acquired via a penetrating globe injury. Some foreign bodies like glass have an inert nature, and the timing of intervention can be delayed, but foreign bodies like metals have a toxic effect on the eye and require urgent removal.

We present a case of a young male with a penetrating globe injury following a road traffic accident. He acquired a foreign body glass piece in his left eye, which was initially missed. Upon thorough examination, it was found at the inferotemporal quadrant of the retina. Considering the inert nature of IOFB and the risks of bleeding and damage to the surrounding intraocular structures, we decided not to remove it. The patient has been stable for four years with good vision in the same eye.
\end{abstract}

KEY WORDS: intraocular foreign body; IOFB; complications of IOFB

Ophthalmol J 2020; Vol. 5, 5-7

\section{INTRODUCTION}

Foreign bodies like glass are easily missed due to their transparent nature. An intraocular foreign body (IOFB) may need urgent removal if there is a risk of developing endophthalmitis $[1,2]$. If the IOFB is inert, it is best to observe because there is a risk of intraoperative bleeding and injuring other intraocular structures during removal.

Here, we present a case of a retained intraocular glass piece following a road traffic accident (RTA). It serves as a challenging case because the glass piece was not removed, and it has stayed inert for four years.

\section{CASE REPORT}

A 28-year-old healthy male presented with a road traffic accident four years ago. His spectacles broke in the accident and he was uncertain whether the glass pieces had penetrated his left eye.

On initial presentation, visual acuity was $20 / 20(-3.25$ DS $)$ in the right eye and hand movement in the left. The right eye looked fine, while the left eye had a scleral tear measuring $9 \mathrm{~mm}$ from the 1 to the 5 o'clock position with hyphaemia. A foreign body glass piece had penetrated through this tear, which was missed until performing B-scan and CT several weeks after the primary repair.

Four weeks following repair, his visual acuity improved to 20/100 with pinhole in the affected eye. Sutures of primary repair were intact, but traumatic cataract developed and fundoscopy showed vitreous haze. B-scan showed vitreous haze inferiorly (Fig. 1). Computed tomography (CT) orbits showed a radio-opaque foreign body within the anteroinferior aspect of left globe measuring $1.8 \times 1.0 \mathrm{~cm}$ and 


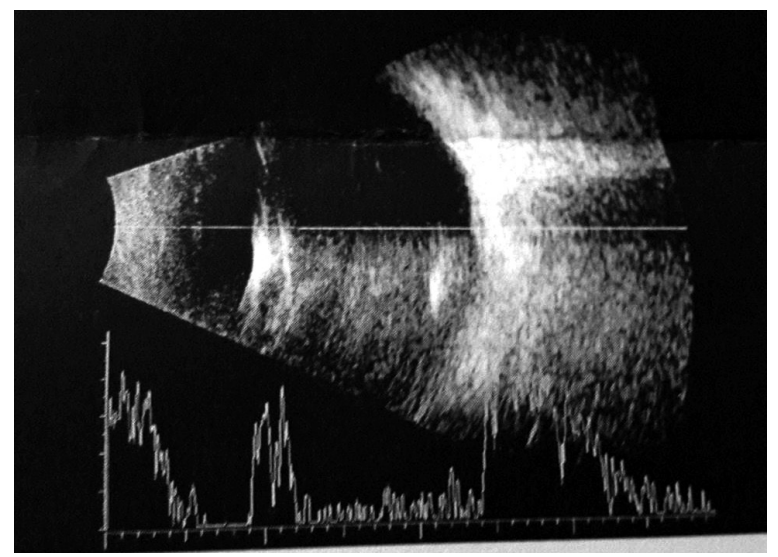

FIGURE 1. B-scan showing vitreous haemorrhage and intraocular foreign body (IOFB) in the left eye

haemorrhage in the posterior chamber (Fig. 2). The traumatic cataract was removed with posterior chamber intraocular lens (PCIOL) placement, and pars plana vitrectomy with air tamponade was performed to remove the vitreous haemorrhage. A glass piece fixed in the inferotemporal quadrant of the retina was visible during vitrectomy, but we decided not to manipulate it because there was a risk of further bleed. On the first postoperative day, his visual acuity was 20/80 with pinhole, anterior chamber was quiet and deep, cornea was clear, and IOL was in place. He was routinely followed, and his visual acuity gradually improved to $20 / 25$ with -3.25 DS in his left eye over a period of six months. The glass piece remained quiescent during his yearly follow-up for four years.

\section{DISCUSSION}

In all cases of RTA, IOFB needs to be excluded, beginning with the history, with particular emphasis on the mechanism of injury. High suspicion for IOFB should always be maintained [2]. Complete ocular examination is highly important to rule out IOFB, even if there is no evidence - a CT scan needs to be done to rule it out.

An intraocular foreign bodies account for almost $40 \%$ of penetrating ocular injuries $[3,4]$. Seventy-five per cent of IOFBs lodge in the posterior segment [5]. They can cause damage to the eye by mechanical injury, introducing infection and exerting a toxic effect to the surrounding structures [6].

The decision regarding IOFB removal is determined by several factors, including the risk of endophthalmitis and the nature of the foreign

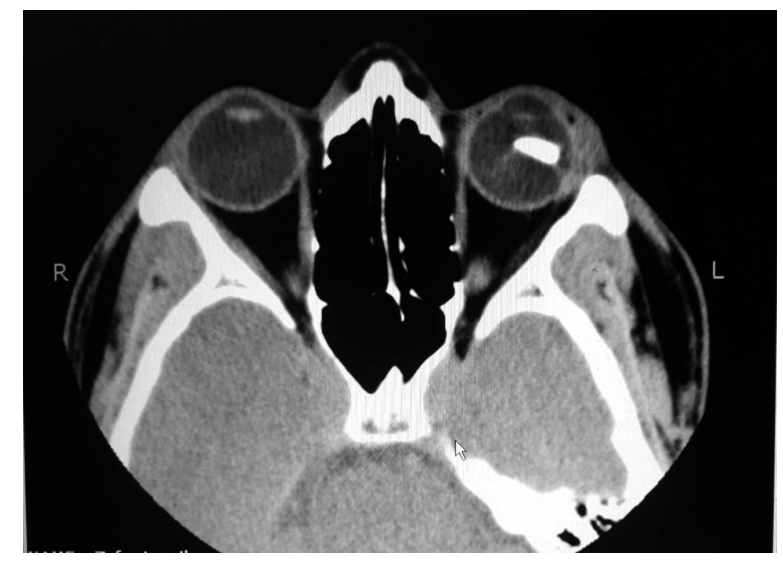

FIGURE 2. Computed tomography (CT) scan showing intraocular foreign body (IOFB) in the left eye

body. If the risk of endophthalmitis is high and the IOFB is metallic in nature, vitrectomy with removal of IOFB should be considered as soon as possible $[1,2]$. If the IOFB is dormant, removal can be delayed, and such patients can be followed up regularly.

Hwi et al. reported a case of an infant who acquired an intraocular glass piece following RTA. The glass piece was lodged between the right optic disc and the fovea. It measured $3.5 \mathrm{~mm} \times 4.0 \mathrm{~mm}$, much smaller than in our case, which measured $1.8 \mathrm{~cm} \times 1.0 \mathrm{~cm}$. In this case, the glass piece was not initially removed. It was later removed when the child gained increased mobility and developed cataract [7]. In certain cases, the inert IOFBs can be left in situ and the patient can be observed over time $[8,9]$.

In our case, the foreign body was not removed because the patient had a vitreous haemorrhage, and removal during vitrectomy could have led to further bleeding by injuring surrounding structures. Considering the risk of intraoperative bleeding and the inert nature of the glass piece, it was left in place. Although our patient had retained IOFB, his visual acuity improved to normal with time, and he has remained stable for four years with yearly follow-up.

\section{CONCLUSIONS}

In all cases of RTA, there should be suspicion of IOFB. Intraocular foreign body should always be ruled out by means of CT scan in adjunct with $\mathrm{B}$-scan. The decision regarding the removal of an IOFB can be deferred in cases where the nature of IOFB is inert, it is fixed in place, and there are risks 
of bleeding and damage to surrounding intraocular structures.

\section{Statement of ethics}

The patient provided written, informed consent for submission of the case report and any accompanying images. This case report was approved by the Ethics Committee of Aga University Hospital, Karachi, Pakistan.

\section{Disclosure statement}

The authors declare that they have no conflicts of interest.

\section{REFERENCES}

1. Kuhn F, Morris R, Witherspoon CD. Intraocular foreign body (posterior segment) . In: Hampton Roy RD. ed. Masters Techniques in Ophthalmic Surgery. Williams and Wilkins, Baltimore 1995: 1201-1212.

2. Katz G, Moisseiev J. Posterior-segment intraocular foreign bodies: An update on management. Risks of infection, scarring and vision loss are among the many concerns to address. Retinal Physician. 2009.

3. Cazabon S, Dabbs TR. Intralenticular metallic foreign body. J Cataract Refract Surg. 2002; 28(12): 2233-2234, doi: 10.1016/s08863350(02)01431-1, indexed in Pubmed: 12498867.

4. Coleman DJ, Lucas BC, Rondeau MJ, et al. Management of intraocular foreign bodies. Ophthalmology. 1987; 94(12): 1647-1653, doi: 10.1016/s0161-6420(87)33239-7, indexed in Pubmed: 3431834.

5. Behrens-Baumann W, Praetorius G. Intraocular Foreign Bodies. 297 consecutive cases. Ophthalmologica. 1989; 198(2): 84-88, doi: 10.1159/000309963, indexed in Pubmed: 2710504 .

6. Ahmadieh H, Soheilian M, Sajjadi H, et al. Vitrectomy in ocular trauma. Factors influencing final visual outcome. Retina. 1993; 13(2): 107-113, indexed in Pubmed: 8337490.

7. Hwi TP, Min TW, Ying CS, et al. Glass piece in the retina after road traffic accident: to remove or not to remove. Sch J Med Case Rep. 2015; 3(9B): 906-910.

8. Greven C, Engelbrecht N, Slusher M, et al. Intraocular foreign bodies: management, prognostic factors, and visual outcomes. Ophthalmology. 2000; 107(3): 608-612, doi: 10.1016/s0161-6420(99)00134-7, indexed in Pubmed: 10711903.

9. Al-Thowaibi A, Kumar M, Al-Matani I. An overview of penetrating ocular trauma with retained intraocular foreign body. Saudi J Ophthalmol. 2011; 25(2): 203-205, doi: 10.1016/..sjopt.2011.01.001, indexed in Pubmed: 23960924. 